\title{
Endoscopic ultrasound-guided fine-needle tissue acquisition - A review and update of literature
}

\author{
Benjamin Tharian, Nayana George ${ }^{1}$, Ashley Canipe, Bronte Holł², Konrad Krall ${ }^{3}$, Shantel Hébert-Magee ${ }^{4}$, \\ Udayakumar Navaneethan ${ }^{5}$, Robert H. Hawes ${ }^{6}$, Shyam Varadarajulu', Muhammad K. Hasan ${ }^{5}$
}

\begin{abstract}
Advanced Endoscopy Fellow, Center for Interventional Endoscopy, Florida Hospital, Orlando, USA, 'Department of Medicine, Western Hospital, ${ }^{2}$ Department of Gastroenterology, St Vincent's Hospital, Melbourne, Australia, ${ }^{3} \mathrm{C} y t o t e c h n i c i a n$, and ${ }^{4}$ Cytopathologist, Center for Interventional Endoscopy, Florida Hospital, ${ }^{5}$ Department of Medicine, University of Central Florida, Interventional Gastroenterologist, Center for Interventional Endoscopy, Florida Hospital, ${ }^{6}$ Department of Medicine, University of Central Florida, Interventional Gastroenterologist and Medical Director, Institute for Minimally Invasive Therapy, Florida Hospital, 'Department of Medicine, University of Central Florida, Interventional Gastroenterologist and Medical Director, Center for Interventional Endoscopy, Florida Hospital, Orlando, USA
\end{abstract}

Abstract $\begin{aligned} & \text { Ever since the first endoscopic ultrasound-guided fine needle aspiration (FNA) was done in } \\ & \text { 1992, the procedure has evolved to become an indispensable tool for tissue acquisition in } \\ & \text { patients with gastrointestinal tumors and periluminal lesions. With the growing evidence } \\ & \text { of neoadjuvant therapy and research into intratumoral therapy, the need to obtain tissue } \\ & \text { diagnosis for tumors is quite apparent. This review provides an overall perspective to the } \\ & \text { endosonographer on various issues that are a key for best practices in FNA, in addition to } \\ & \text { being an update for practicing experienced endosonographers. }\end{aligned}$
Key words
$\begin{aligned} & \text { Cytology, endoscopic ultrasound, fine-needle aspiration, fine needle core biopsy, molecular } \\ & \text { markers, rapid onsite cytologic evaluation, tissue acquisition, training }\end{aligned}$

\section{Introduction}

Endosonography has evolved over the last two decades and become an integral tool, slowly replacing rather than just being an adjunct to interventional radiology. ${ }^{[1,2]}$ Endoscopic ultrasound-guided-fine-needle aspiration (EUS-FNA) and EUS-guided fine needle biopsy (EUS-FNB) are principal techniques applied to diagnose malignancy. The ability to place a needle into suspicious lesions safely and accurately is what has made EUS indispensable in the evaluation of patients with solid tumors. ${ }^{[3]}$ Advances in EUS-FNA help us not only in staging of tumors, but also in the treatment and prognostication of the same. ${ }^{[4]}$ It is important to be cognizant of the fact that the technology has to be tailored to the individual patient, with no single right answer to all challenges one might encounter. In this comprehensive review of the latest literature, we have

\section{Access this article online}

\begin{tabular}{|l|l|}
\hline \multirow{2}{*}{$\begin{array}{l}\text { Website: } \\
\text { www.jdeonline.in }\end{array}$} & Quick Response Code \\
\hline DOI: & \\
10.4103/0976-5042.155230 & \\
\hline
\end{tabular}

discussed various factors that determine the outcomes of EUS-guided tissue acquisition and a practical evidence-based approach to improve the yield.

\section{Indications and Contraindications}

The important diagnostic indications are for the diagnosis and staging of esophageal and lung tumors, pancreatic assessment (masses, cysts, and benign pathology), sampling of mediastinal, perirectal, and retroperitoneal nodes, left hepatic lobe and adrenal and for assessment and guiding treatment of sub epithelial lesions. Therapeutic applications of EUS-FNA needle are rapidly expanding and range from pseudocyst and biliary drainage, fiducial insertion for stereotactic radiotherapy to potential for targeted therapy.

Endoscopic ultrasound-FNA should not be done in situations when it is unlikely to alter the management or when the risk outweighs the benefits. Its contraindications are similar to those of any endoscopy. Moreover, EUS-FNA is not generally advocated when good views cannot be obtained or when there is a major blood vessel or tumor on the way to the target with high risk of seeding. In addition, it should be borne in mind that EUS-FNA is seldom an emergency procedure. Hence it has to be done preferably electively in a hemodynamically stable patient.

Address for correspondence:

Dr. Benjamin Tharian, Center for Interventional Endoscopy, 601 East Rollins Street, Orlando, Florida, 32803, Orlando, USA. E-mail: benjamintharian@yahoo.co.in 


\section{Precautions}

The general precautions for FNA are similar to those for any therapeutic endoscopic procedure. ${ }^{[5]}$ It is preferable to discuss the issue of antiplatelets and anticoagulation with the patient's cardiologist in advance. Low dose Aspirin could however be continued, while clopidogrel and newer antiplatelet agents have to be withheld for at least a week. Warfarin is withheld 5 days before and bridged with heparin if high risk. Low molecular weight heparin is withheld $12-24 \mathrm{~h}$ while unfractionated heparin $6 \mathrm{~h}$ prior to FNA. Most of the newer anticoagulants are held off for a minimum of $48 \mathrm{~h}$, though 5 days ideally, after consulting with hematologist. Patients at high risk of sedation, which is mandatory for EUS, those with surgically altered anatomy precluding access to the head or uncinate process of pancreas and lack of an avascular window due to collaterals, may be indications to prefer percutaneous over EUS acquisition. ${ }^{[6]}$

\section{The Scopes and Needles}

The procedure requires curvilinear echoendoscopes (EUS) that are produced by three leading manufacturers: Olympus (Olympus Medical Systems Inc., Tokyo, Japan), Pentax (Pentax, Tokyo, Japan) and Fujinon (Fujifilm Corp., Tokyo, Japan). ${ }^{[4]}$ They provide a plane of imaging parallel to the long axis of the endoscope, with the transducer placed at its tip and thus enabling real-time targeted tissue sampling. The channel size must be at least $2.8 \mathrm{~mm}$ for passing accessories including needles. Exit angle is altered using the up/down wheels, movement of the scope and sometimes using the elevator. Excessive reliance on the latter can distort the needle. The forward viewing scope launched recently, has so far failed to become popular, despite the theoretical advantage of better access, optimal precision, and more efficient transfer of force. ${ }^{[7]}$

Currently, available needles are of the 19, 22, and 25 gauge (Cook-echo-tip, Quick-core and ProCore, Mediglobe-Sonotip II, Olympus-Power-shot and EZ-shot, Boston Scientific-Slim line and finally the Beacon Endoscopic needle) ${ }^{[8]}$ All needles have a removable stylet and some have an adjustable sheath to fit the working channel of the scope precisely. Finer needles are designed for cytology, though cell blocks might give comparable yield to the core biopsy. ${ }^{[9,10]}$ A 19G needle made of nitinol (Fle $\times 19$; Boston Scientific, Natick, MA, USA) has been shown to have enhanced flexibility especially for transduodenal aspirations. ${ }^{[1]} \mathrm{A}$ new 22-gauge needle from Olympus with prototype side-port has shown encouraging results for cytology, though further data are awaited. ${ }^{[12,13]}$

\section{The Basics of Specimen Staining and Cytopathology}

Two types of smears are commonly made. Air-dried smears are stained rapidly with Diff-Quik (Dade Diagnostics, Miami, FL) and used for rapid onsite cytologic evaluation (ROSE). This is followed by fixation using Alcohol to preserve the nuclear features and staining by papanicolaou or hematoxylin and $\operatorname{eosin}(\mathrm{H}$ and $\mathrm{E})$ stains. When initial cytology is indeterminate, combining with fluorescence in situ hybridization (FISH), proteomics and $\mathrm{K}$-ras/p53 analysis may improve the yield. ${ }^{[14-17]}$

\section{Cytology or histology}

The main thrust for development of a Trucut needle with EUS stems from the limited ability to determine the biological behavior and architecture from cytology, less dependence on ROSE and the belief that it would reduce the number of passes and acquisition time, resulting in better patient turnover.

However, in most cases, cytology specimen alone is sufficient to arrive at a diagnosis. The sensitivity of EUS-FNA is superior only when adequacy is assessed with ROSE. ${ }^{[18]}$ Histology would provide better assessment of tumors, definitive for benign diseases, to distinguish primary from secondary tumors, whenever molecular markers are sought, for tissue profiling and cell culture for personalized targeted therapy and possibly when on-site cytopathology is unavailable. ${ }^{[10]}$ For lesions that may require special staining or a degree of architectural integrity, cell-block preparation is recommended. We had demonstrated that the accuracy of Trucut needle biopsy (TNB) was lower than that of EUS-FNA, though not statistically significant. ${ }^{[19]}$ We believe that the limited on-site, real-time interpretation for specimen adequacy in case of core biopsies and poor design of the currently available needles might be responsible.

For preparing a cell-block, the FNA specimen is placed into liquid media (CytoLyt [methanol-water solution], CytoRich Red, RPMI-1640 (Roswell Park Memorial Institute) or HBSS (Hanks' Balanced Salt Solution)) and sent to the laboratory where it is spun into a pellet in combination with a clotting agent (plasma and thrombin, albumin or histogel), formalin-fixed, paraffin-embedded, and sectioned for standard $\mathrm{H}$ and $\mathrm{E}$, staining. Liquid-based cytology (Thin prep; Cytyc, Inc., Marlborough, MA, and SurePath; TriPath, Inc., Burlington, $\mathrm{NC}$ ) is an automated process designed to minimize the technical problems. ${ }^{[20]}$ This method provides high cell preservation and uniform monolayer dispersion of cells. However, it is expensive and may lead to loss of background mucin, which could delay the diagnosis of mucin-producing pancreatic tumors.

The term EUS-guided fine-needle tissue acquisition often refers to histologic procurement using FNA needle (initially used only for procedures done using the Alliance II inflation-continuous negative suction system from Boston Scientific) to distinguish it from standard EUS-FNA. ${ }^{[10]}$ The recommendation, though not evidence based, is to do at least three passes with a $19 \mathrm{G}$ needle and four or more with a 22 or $25 \mathrm{G}$ needle to get adequate core. It is ideally required for lymphoma, mesenchymal tumors, autoimmune pancreatitis, well-differentiated adenocarcinomas, and those with a persistently negative FNA suspected to be falsely negative, due to high index of suspicion. ${ }^{[10,21]} \mathrm{An}$ on-site 
cytology assessment is possible by a "touch prep" using the above core.

\section{Rapid on-site evaluation}

The endosonographer should realize the role of a cytopathologist in the team and the need to provide them with adequate clinical information. Committing to a diagnosis with a pauci-cellular sample is a common reason for misinterpretation by the cytopathologist. Hence, all measures should be taken to improve the yield when sampling solid pancreatic masses in the setting of chronic pancreatitis. It has been clearly demonstrated in several studies that, the presence of an on-site cytopathologist is critical to improve the diagnostic yield, decrease the number of unsatisfactory samples, and minimize the number of passes required. ${ }^{[22]}$ Erickson et al. concluded that the absence of ROSE would result in a $10-15 \%$ reduction in definitive diagnosis and make the unit inefficient. ${ }^{[23]}$

In a recent national questionnaire survey, over $75 \%$ of endosonographers in the US utilized ROSE in their labs, confirming their popularity. ${ }^{[24]}$ Most units have at least a cytotechnologist with an aim of reducing the nondiagnostic samples. Incorporation of ROSE has helped overcome several diagnostic pitfalls and improved our productivity and client satisfaction significantly. ${ }^{[1]}$

Rapid onsite cytologic evaluation not only helps with assessment of the adequacy of the sample, but also provides recommendation on collection of additional samples for ancillary studies and an attempt to provide a preliminary diagnosis the same day. ${ }^{[25]}$ The sampling location and technique can be altered if initial samples are nondiagnostic, in addition to enabling timely referral for surgery or to the oncologist. ${ }^{[1]}$ The endosonographer should be able to handle the specimen and evaluate for diagnostic accuracy, especially when ROSE is unavailable. ${ }^{[26]}$ Gross visible assessment of the slide, looking for particulate material/specimen, should be a quick means to decide on the slides to be examined under the microscope. Likewise "gross" assessment of core biopsy specimen and mucus is easily done. This might improve sonographer confidence and would be a step toward dynamic telecytopathology, which could become a reality in the future. ${ }^{[27]}$

\section{Evidence Based Acquisition Technique}

The proficiency in performing EUS-FNA cannot be based just on an arbitrary number, though the recommendation from the American Society for Gastrointestinal Endoscopy in 2001 has been a minimum of 150 supervised cases (75 being pancreatobiliary), with 50 EUS-FNA (at least 25 being pancreatic), ${ }^{[28]}$ though the more recent British Society of Gastroenterology recommendation in 2011 was for 75 FNA of which at least 45 are likely pancreatic adenocarcinomas. ${ }^{[29]}$ However, ongoing training is essential until competency is measured objectively, irrespective of the caseload due to variation in the learning curves. ${ }^{[30]}$ EUS-FNA is a flawless procedure that provides high quality "diagnostic" sample and requires not only the expertise of the endosonographer, but also a review of the clinical indication, correct selection of needles, use of evidence-based strategies such as fanning, in addition to access to a reliable cytopathology service. The topic has been discussed under the following seven subheadings, which address various factors that independently influence the outcome and yield of the technique.

\section{The Selection of Needle}

Various needles are commercially available as discussed above. The choice of needle depends on the anatomical location of the target, which in turn determines the degree of flexibility required, yield and safety, ability to obtain core tissue, the nature of target-solid or cystic and endosonographer preference.

Randomized controlled trials (RCT) have shown that $22 \mathrm{G}$ and $25 \mathrm{G}$ needles have similar overall diagnostic accuracy, though there was a trend in favor of $25 \mathrm{G}$ for transduodenal sampling, most likely related to the flexibility of the latter despite the angulation of the echoendoscope. ${ }^{[31-33]}$ Two meta-analyses have shown $25 \mathrm{G}$ to be superior with higher sensitivity for diagnosing pancreatic malignancy. ${ }^{[1,34-36]}$ Itoi et al. and Yasuda et al. were the first investigators to demonstrate use of standard 19G FNA needle for tissue procurement. ${ }^{[37,38]}$ Another RCT comparing $19 \mathrm{G}$ and $22 \mathrm{G}$ needles for pancreatic and peripancreatic lesions showed superior accuracy and tissue acquisition using the former, though higher technical failure rates in the head/uncinate process due to obvious reasons. ${ }^{[39]}$ A recent multicenter RCT by Varadarajulu et al. showed comparable accuracy and failure rates between 19 and $25 \mathrm{G}$ needles for pancreatic pathology, though core biopsies were significantly more with the former ( $86 \%$ vs. $33.3 \%){ }^{[11]}$ The study by Larghi et al. with 19G FNA needle showed adequate histology in $97.5 \%$ with a technical success rate of $99.2 \%$, the major limitation being complete exclusion of a difficult lesion, namely pancreatic head/uncinate masses. ${ }^{[40]}$ The $19 \mathrm{G}$ should be used with caution by less experienced endosonographers due to the technical difficulties, due to certain challenging positions within the duodenum. ${ }^{[39]}$

With regards to diagnostic aspiration from cystic lesions, our own practice has been to use the $22 \mathrm{G}$ needle for any cyst smaller than $2 \mathrm{~cm}$, flexible $19 \mathrm{G}$ needle for transduodenal aspiration and any $19 \mathrm{G}$ needle for other routes of aspiration. ${ }^{[1]}$ One should try to aspirate the cyst with just one pass to minimize the possibility of introducing infection. Despite this, intraprocedural antibiotics are given in addition to a 3-5 days course of oral antibiotic as prophylaxis. ${ }^{[41]}$

The 19G ProCore needle (Cook Medical, Winston-Salem, NC, USA) with "reverse bevel" technology has a positive histologic 
yield in the majority with an accuracy over $90 \%$, compared to the predecessor 19G Trucut from the same company. This needle has a lateral opening of varying length (depending on needle size) that hooks and cuts the tissue, entrapping it into the needle. ${ }^{[10]}$ Iwashita et al. showed that use of $25 \mathrm{G}$ ProCore needle in solid pancreatic tumors (though gave a core in only $32 \%$ ) had a sensitivity, specificity, and accuracy in combined cyto-histologic results of $85 \%, 100 \%$, and $86 \%$ for single pass and $96 \%, 100 \%$, and $96 \%$ on multiple passes, respectively. ${ }^{[42]}$ Overall the 22 and 25G ProCore needles have not been shown to be superior to the FNA needles in its diagnostic accuracy. ${ }^{[43-46]}$ In our experience, the overall efficacy of the biopsy needles over EUS-FNA is modest, with no significant difference in complication rates. DiMaio et al. recently concluded that the most commonly used needle in their survey of endosonographers in the US was the 22G. ${ }^{[24]}$

In a recent meta-analysis, our group showed that the ProCore needle is not superior to a standard FNA needle in yielding neither histology nor cytology (Bang JY, Hawes RH, Hasan MK, et al. EUS-Guided Tissue Acquisition: Meta-Analysis Comparing the ProCore and Standard FNA Needles. Gastrointest Endosc 2014;79:AB427). The main disadvantage of the EUS-guided Trucut biopsy is the lack of a needle designed on a "cutting concept" that would yield samples along multiple trajectories in a single pass, rather than the currently available "slicing" needles that work on a spring/ sliding mechanism. The ProCore needle although originally designed for procuring histologic sample, yields an earlier and better cytologic specimen than a reliable histology. ${ }^{[45,47,48]} \mathrm{We}$ recommend using a flexible $19 \mathrm{G}$ needle in the rare instance a core biopsy is desired. Further research is needed in the design of better core biopsy needles to attain adequate histology. The adoption of an algorithmic approach for EUS-FNA in our unit has been cost effective with better outcomes. ${ }^{[49]}$

Regardless of the type of needle used, passes should be made only under direct endosonographic guidance. If a needle trajectory cannot be visualized, it is possible that the needle is bent and might need to be straightened manually or replaced. Releasing the controls including the elevator and the big wheel, while withdrawing the needle in between passes, and avoiding force to push it out of the scope (which could also damage the scope channel), could minimize this.

\section{Challenging Locations}

It is a known fact that the ease of EUS-FNA diminishes as one goes from the esophagus through the stomach and duodenal bulb to the second part of the duodenum. The scope is reasonably straight when attempting to sample via the trans-esophageal or trans-gastric routes, the only exception being trans-fundic in complete retroflexion, which is seldom needed. For transduodenal access, which is where most of the pancreatic cancers are located (head or uncinate process), the needle could be advanced by straightening the tip of the scope and then the scope repositioned for FNA. Shortening of the echoendoscope and release of the "up-down" knob helps while a long and stable scope could bent the needle making it dysfunctional. ${ }^{[1]}$ Air suction or inflation of the balloon could be used to stabilize the position. Sometimes, one might have to load the needle within the gastric lumen or adjust the position of the sheath and the torque in cases of failed duodenal release. As mentioned, the 19G needle reduces the maneuverability further, hence the smaller ones usually preferred due to its flexibility. ${ }^{[50]}$ Larghi et al. recommend use of the $19 \mathrm{G}$ needle without the stylet before insertion into the working channel, to increase flexibility and performance. ${ }^{[40]}$

\section{Use of Stylet}

Once the needle is within the target, the stylet is pushed forward slightly, to expel any needle tract tissue, and then slowly removed from the needle. The stylet prevents the tissue along the path of the needle (i.e., esophageal, gastric or duodenal) to the target, from contaminating the specimen. However, its use can be labor-intensive and increases needle-stick injury. One trial had shown stylet to increase the diagnostic yield, as well as demonstrating air flushes to be a better way of expression of the specimen. ${ }^{[51]}$ Three randomized trials have shown that the use of a stylet did not improve the diagnostic yield for malignancy and always increased the blood. ${ }^{[2]}$ In fact one study showed that the sample adequacy was better without the stylet and in all 3 trials the use of a stylet increased the bloodiness of the specimen. ${ }^{[52-54]}$ The bottom line is that for the first pass, one could still use the stylet, since it comes preloaded, but not thereafter, though it is still handy to express the aspirate onto the slide. ${ }^{[2]}$

\section{Use of suction}

Another controversy is the use of suction at the time of FNA. ${ }^{[5]}$ This would by logic improve the quantity but not the quality, due to the specimen getting bloody, especially in the case of lymph nodes. Larghi et al., recommended use of negative suction of $10 \mathrm{ml}$ syringe for at least $30 \mathrm{~s}$ prior to three to and fro movements within the target. ${ }^{[45]}$ Trials to date have not proven that this technique does improve the yield. ${ }^{[56,57]}$ Suction has to be obviously used for cystic lesions and may be helpful for dry lesions like chronic pancreatitis. ${ }^{[2]}$

A recent blinded randomized study showed wet suction to be superior to dry suction, with significantly higher cellularity and diagnostic yield, without difference in the bloodiness of the specimen (Attam R, Arain M, Bloechi SJ et al. Wet suction FNA technique: A novel technique for EUS-FNA. Results of a prospective randomized and blinded study. Gastrointest Endosc 2014;79:AB110). The needle is flushed with saline prior to puncturing the target and then suction applied. Randomized trials are needed before adopting this.

\section{Capillary Technique}

The other widely used technique is "capillary" or "wicking", also known as "slow pull" technique. ${ }^{[1]}$ This is performed by 
slow withdrawal of the stylet by the endoscopic technician while the needle (within the target), is fanned across the lesion. The principle is generation of a small negative pressure, which increases yield without aspirating excessive blood (contaminating the field), unlike standard suction technique. This technique has been shown to have higher diagnostic sensitivity though cellularity is less, especially with a $25 \mathrm{G}$ FNA needle. ${ }^{[58]}$

\section{Fanning Technique}

It is very well-known that the center of a pathological target often would be necrotic due to compromised blood supply. Hence as with biopsies elsewhere in the body, FNA is done from the periphery of the lesion, which would have the highest potential to yield a diagnostic sample. A better technique to obtain a representative sample that is least bloody is by passing the needle radially across the lesion along varying trajectories, by moving preferably the "up/down" knob. The use of the elevator can sometimes bend the needle affecting its function. We refer to this as the " $4 \times 4$ rule" - needle thrown 4 times along 4 different trajectories, across the lesion, starting from one margin to the other. ${ }^{[59,60]}$ In the case of FNB especially with the 19 G needle, we advocate the " $4 \times 2$ " or " $4 \times 3$ rule," with no more than three jabs, to minimize the sample being bloody.

\section{Number of Passes}

The goal of every endosonographer should be to obtain the diagnostic sample with the minimum number of passes. The availability of rapid on-site cytopathologic evaluation, improves the efficiency of the service, with earlier diagnosis with less number of passes. ${ }^{[22,61]}$ When ROSE is not available, the general recommendation would be to obtain at least five passes with cell block or three for core biopsy and three for FNA of lymph nodes. ${ }^{[2,59]} \mathrm{In}$-room confirmation is rapidly becoming a fundamental part of the integrated, multidisciplinary care of patients with cancer. ${ }^{[62]}$ This sometimes facilitates preoperative assessments and specialist evaluation on the same day. ${ }^{[63]}$

Evidence does not support doing more than 7 passes in a solid mass and 5 in a lymph node to improve yield, owing to the increasing bloodiness of the specimen aspirated, what we describe as the "point of diminishing return." ${ }^{[63,64]}$ As expected, the greater the experience of the endosonographer, the less would be the number of passes required. ${ }^{[65]}$ Diagnostic accuracy plateaus over time despite increasing operator experience.

\section{Dealing with Indeterminate Samples and Special Situations}

Eltoum et al. showed that implementation of EUS-FNA program significantly improved the accuracy of cytologic diagnosis, reduced the number of indeterminate diagnoses, and replaced the need for tissue biopsy. ${ }^{[66]}$ This can however happen in the best of the hands, with the common situation being sampling for suspected cancer in a background of chronic pancreatitis or an uncinate process mass, which becomes even more difficult because of the dense peri-tumoral fibroblast rich stroma (desmoplasia) interfering with aspiration. There is currently no universally accepted protocol in the management of these difficult cases, where one has a high index of suspicion but negative FNA. ${ }^{[2]}$ They could either be followed-up clinically and radiologically for 3-4 months followed by a repeat EUS-FNA, undergo surgical exploration or less favorably CT-guided biopsy (due to the theoretical risk of seeding). ${ }^{[2]}$ In patients with a high index of suspicion of malignancy, the best option is often surgical resection.

From the above discussion, it is clear that cytology and histology are clearly complementary and that TNB might provide incremental value, especially when FNA has been inconclusive. The dictum of needing more passes in a well-differentiated tumor holds true. ${ }^{[6]}$ Repeat EUS-FNA is considered in borderline surgical candidates, those with lower degree of suspicion for malignancy and based on patient/oncologist/surgical choice of repeat tissue acquisition. ${ }^{[6,69]}$ The diagnostic accuracy of a repeat EUS-FNA is over $60 \% \cdot{ }^{[68-70]}$ Addition of K-ras/p53 and FISH may improve the yield. ${ }^{[7]}$ MicroRNA (miRNA) sequences recovered from both formalin-fixed and FNA specimens are promising objective biomarkers, which would certainly help reduce indeterminate results. Brand et al. had recently shown in their multicenter validation trial that, the combination of cytology and 5-miRNA classifier could accurately predict specimens that contain cancer, with an overall sensitivity of up to $91 \%$, specificity of $96 \%$, and a positive predictive value over $99 \% .{ }^{[72]}$

Our group has shown that the presence or absence of a biliary or pancreatic stent does not have any impact on the yield of the EUS-FNA. ${ }^{[73-75]}$ It could sometimes be a useful tool in targeted FNA from an indeterminate stricture.

Technological advances such as EUS elastography, contrast-enhanced Doppler EUS, contrast-enhanced harmonic EUS (CH-EUS), and EUS spectrum analysis aid in further characterization of lesions already detected by EUS. ${ }^{[5,76]}$ Thus, they help narrow down the differential diagnoses, targeting the needles for tissue acquisition and minimizing indeterminate results. Elastography distinguishes normal from pathological tissue on the basis of its elasticity (red hue suggesting soft lesion and blue hard tissue), thus complementing EUS. ${ }^{[77]}$ However, these are still evolving and far from replacing EUS-FNA, not that reproducible and yet to gain popularity amongst endosonographers due to the learning curve and lack of randomized trials supporting its role. ${ }^{[77]}$ Moreover, these techniques could be used as a noninvasive modality in situations where EUS-FNA is considered a contraindication, especially when the accessing the lesion involves crossing an uninvolved nearby organ (increasing the risk of seeding) or a major blood vessel. Giovannini et al. introduced the qualitative 
scoring system, with an overall accuracy of $89.2 \%$ compared to $94 \%$ when one adopts the Iglesias-Garcia classification. ${ }^{[78,79]}$ These techniques are yet to gain universal acceptance. ${ }^{[80]}$

Contrast-enhanced-EUS is useful for characterizing pancreatic lesions and can detect pancreatic adenocarcinomas with a sensitivity of $94 \%$ and a specificity of $89 \%$ as a result of the hypo-enhancement of these lesions. Malignant potential of gastrointestinal stromal tumors and differentiation between malignant and benign lymphadenopathy might also be feasible with $\mathrm{CH}$-EUS. Indeed, it complements EUS-FNA in those with indeterminate or negative results. ${ }^{[81]}$ The commonly used intravenous agent in Europe is microbubbles of sulfur hexafluoride (Sono-Vue; Braco, Milan, Italy), with an arterial phase in $10-30 \mathrm{~s}$ and a late venous phase in $30-120$ s. $^{[76]}$ Use of the vascularity index and hypovascularity as a marker of pancreatic malignancy, increases sensitivity to $92 \%$ and yields a specificity of $100 \% \cdot{ }^{[82-86]}$ As long as surgery and multimodality management decisions are based on histopathology and not just imaging characteristics, real-life utility of these advanced techniques would be questioned, until there is evidence to show their role in targeting the needle.

\section{Cytogenetics and Molecular Markers - the Future}

The Papanicolaou Society of Cytopathology has provided guidelines on the use of ancillary testing in the cytologic diagnosis of biliary and pancreatic lesions. Loss of immunohistochemical staining for the protein product of SMAD4 gene and staining for mesothelin support the diagnosis of ductal adenocarcinoma. ${ }^{[21]}$ Markers for endocrine and exocrine differentiation aid in the diagnosis of endocrine and acinar tumors, while nuclear staining for beta-catenin supports a diagnosis of solid-pseudopapillary neoplasm. Cyst fluid analysis for amylase, CEA, and a number of gene mutations (KRAS, GNAS, von Hippel-Lindau, RNF43 and CTNNB1) may aid in the diagnosis of cystic neoplasms. ${ }^{[21]}$ Proteomics and other molecular tests in mucinous neoplasms, although appear to be promising and improve diagnostic sensitivity, are currently not cost effective tools. ${ }^{[15-17]}$

Fifteen percent of GISTs are wild type and negative for mutations in KIT and PDGFRA. Other oncogenic drivers, including mutations in NF type I, RAS genes, BRAF, and subunits of the succinate dehydrogenase complex are responsible in this wild group, with the general recommendation to do routine genotyping with a core biopsy sample, as the type and dose of Tyrosine kinase inhibitor treatment used is dependent on the mutation identified. ${ }^{[87-89]}$

There is increasing interest in the analysis for prognostic markers in pancreatic cancer in the EUS-FNA specimen. Preoperative determination of $\mathrm{Ki}-67$ proliferation index, a prognostic marker for pancreatic nonfunctional neuroendocrine tumors is possible in over $93 \%$ of those with a tissue specimen. ${ }^{[90]}$
Nguyen et al. described immunohistochemical analysis of the tissue samples for S100A2 and S100A4 protein expression that predict poor prognosis. ${ }^{[11]}$ Further research on the above might help in more careful selection of candidates for surgery or other multimodality treatment, thus attempting to avoid futile treatments in a terminal patient, enabling better utilization of the limited resources and overall outcomes.

\section{Pitfalls in Endoscopic Ultrasound-Fine Needle Aspiration}

This includes low yield for diagnosis of pancreatic malignancy in a background of chronic calcific pancreatitis or in cystic lesions and false positive diagnosis of stromal tumor (GIST) and metastasis when contaminated by smooth muscle cells from bowel wall or normal epithelial cells during needle passage. ${ }^{[92]}$

In a retrospective study of over 18,000 EUS procedures, needing FNA in $31.4 \%$, false positive rate was shown to be $5.3 \%$, which increased to $7.2 \%$ on including "false positive-suspicious" results. The cytohistologic discordance was higher for nonpancreatic FNA (15\%) that predominantly included periluminal nodes compared to $2.2 \%$ in pancreatic FNA. ${ }^{[93]}$ The root causes noted were contamination with epithelial cells, EUS sampling error, and pathological misinterpretation. Potential pitfalls occurred mostly in the setting of Barrett's with dysplasia or early cancer, chronic or autoimmune pancreatitis, reactive gastropathy, and rectal cancer staging. Any situation with inflamed or abnormal interposed mucosa, or where there is a possibility of the exfoliated cell being carried to a distant site, should alert the clinician and cytopathologist. There is a need for cytohistological correlation as an internal quality assurance measure and also to limit the discordance, for better patient outcomes. This would also improve with better correlation with enhanced imaging and use of more accurate immunocytochemical and molecular markers. ${ }^{[93]}$

In the setting of chronic pancreatitis, a conglomeration of lobulations could mimic a mass, while the acoustic shadowing from stones could mask a pancreatic mass. ${ }^{[94]}$ Chronic pancreatitis as mentioned earlier is challenging due to both false positive and false negative EUS-FNA results. ${ }^{[94]}$ Moreover, the collateral vasculature and reverberations from a stent could also adversely affect choice of sampling site. Presence of occasional atypical cells, with degenerative vacuoles and mitosis adds to the confusion. We showed that the median number of passes required for establishing the diagnosis of cancer in a patient with chronic pancreatitis was five versus only two in an otherwise normal pancreas. ${ }^{[95]}$ The general consensus is to perform a minimum of seven passes to improve the yield, using "fanning" technique if the index of suspicion is high and even using suction if the tap is dry. Elastography, contrast ultrasound, rapid onsite evaluation (ROSE), and molecular markers, though still not uniformly available, have all been used with varying degrees of success. 


\section{Adverse Events Associated with Endoscopic Ultrasound-Fine Needle Aspiration}

The mechanical and optical differences of an echoendoscope are more challenging than those of a side viewing endoscope, especially due to the stiff distal ultrasound probe. Perforation especially cervical esophageal and that of the duodenal apex can be minimized by gaining more hands-on training, careful manipulation of the scope and by avoiding the use of excessive force to blindly maneuver on encountering unusual resistance. ${ }^{[96]}$ Change of neck tilt, shoulder lift and abdominal pressure, use of a partially inflated balloon and sufficient lubrication helps, although it is sometimes safer to verify normal anatomy (thus eliminating a diverticulum or stricture) with a gastroscope, especially in those patients who have not had one done recently. ${ }^{[97]}$ Adverse events associated with sedation and standard techniques are not discussed here. ${ }^{[5,41]}$

Endoscopic ultrasound-guided FNA is a useful adjunct that facilitates safe and reliable sampling of submucosal lesions and peri-luminal pathology, with significant clinical impact. ${ }^{[98]}$ The risk of mediastinitis despite prophylactic antibiotics after aspiration of a cyst has to be carefully weighed against the benefits. ${ }^{[99,100]}$ There have been isolated reports of retroperitoneal and peri-rectal abscess following celiac blocks and peri-rectal FNA, respectively, and cholangitis after FNA of a hepatic lesion. ${ }^{[5,101]}$ The overall incidence of pancreatitis following FNA is $0.44 \%$ with $75 \%$ being mild and major morbidity is related to pancreatic duct leak and development of pancreatic ascites and pseudocyst. ${ }^{[101-103]}$ The risk can be reduced by minimizing the length of normal pancreatic parenchyma that the needle has to course through, avoiding puncturing of the main duct or obstructed upstream side branches and delaying FNA in the setting of acute pancreatitis. The incidence of biliary peritonitis as an adverse event from a diagnostic FNA is low, though higher when EUS guided biliary drainage is used as a salvage therapy when ERCP fails. ${ }^{[104-106]}$

There have been few anecdotal reports of malignant seeding of the needle track, that were lower than those associated with percutaneous sampling. ${ }^{[107-109]}$ More recent studies have shown that preoperative EUS-FNA of pancreatic neoplasms was not associated with an increased risk of seeding or decreased overall survival. ${ }^{[110-113]}$ The chance of seeding is less with EUS due to the shorter needle track and the likely inclusion of the track in the surgical specimen, especially for pancreatic head lesions, which would need Whipple's resection. ${ }^{[6]}$ However, due to the theoretical risk of seeding and isolated case reports, EUS-FNA is avoided in patients with hilar cholangiocarcinoma, who might be potential candidates for liver transplantation. These patients would benefit from ERCP and brush cytology or cholangioscopy for tissue diagnosis. ${ }^{[114-117]}$
Adverse events associated with EUS and EUS-FNA is likely to increase with wider therapeutic applications. Hence careful patient selection and documentation of an informed written consent are very important. Immediate recognition of an adverse event is vital and prompt action leads to better outcomes.

\section{Take Home Messages}

The ultrasound probe should ideally be positioned as close to the target as possible with a straight scope. Fanning has to be incorporated into every procedure to improve efficiency and yield. The current evidence and our recommendation would be to use suction only in case of dry aspirates or cystic lesions and a stylet to be used only for controlled expression of the aspirate and not with a view to increasing the yield. Concept of diminishing return should be clearly driven home. Incorporation of ROSE would enhance efficiency with better outcomes. Molecular markers are increasingly used in selected cases. Antibiotic prophylaxis has to be given to any patient undergoing aspiration of cystic lesion.

The choice of FNA or FNB should be guided by the clinical need, locally available expertise, including a reliable cytopathologist. Having a basic understanding of cytopathology would be useful for an endosonographer. Collaboration between cytopathologists and endosonographers is to be encouraged.

The main areas of research are still focused on improvising the devices and techniques, a mine field of therapeutic EUS and advances in cytopathology. Despite the current evidence, a recent national survey among endosonographers in the US showed striking variation in the FNA practices, related to the EUS volumes and the working environment, suggesting scope for improvement. ${ }^{[24]}$ Incorporation of an algorithmic approach like the one we had suggested, would improve not only resource utilization but also the clinical outcomes. ${ }^{[49]}$

Preprocedural planning, review of clinical notes, indication and available imaging, open discussion with the patient and family along with documentation of a written informed consent, being aware of one's own limitations and available local expertise and last but not the least, knowing when to call for help, would limit undesired and adverse outcomes for the patient and the endosonographer.

\section{Conclusion}

In this review, we have attempted to provide a snap shot of best practices in EUS-FNA. Awareness and acceptance of the roles, benefits, and impact of endosonography over alternative interventions has increased over the last decade. The future looks promising with better training of endosonographers, improvised techniques, higher definition endosonography, objective molecular diagnostic and prognostic markers and a more widespread use of ROSE. 


\section{References}

1. Holt BA, Varadarajulu S, Hébert-Magee S. High-quality endoscopic ultrasound-guided fine needle aspiration tissue acquisition. Adv Ther 2014;31:696-707.

2. Varadarajulu S, Fockens P, Hawes RH. Best practices in endoscopic ultrasound-guided fine-needle aspiration. Clin Gastroenterol Hepatol 2012;10:697-703.

3. Hasan MK, Hawes RH. EUS-guided FNA of solid pancreas tumors. Gastrointest Endosc Clin N Am 2012;22:155-67, vii.

4. Tharian B, Tsiopoulos F, George N, Pietro SD, Attili F, Larghi A. Endoscopic ultrasound fine needle aspiration: Technique and applications in clinical practice. World J Gastrointest Endosc 2012;4:532-44.

5. ASGE Standards of Practice Committee, Early DS, Acosta RD, Chandrasekhara V, Chathadi KV, Decker GA, et al. Adverse events associated with EUS and EUS with FNA. Gastrointest Endosc 2013;77:839-43.

6. Chaya C, Nealon WH, Bhutani MS. EUS or percutaneous CT/US-guided FNA for suspected pancreatic cancer: When tissue is the issue. Gastrointest Endosc 2006;63:976-8.

7. Larghi A, Fuccio L, Chiarello G, Attili F, Vanella G, Paliani GB, et al. Fine-needle tissue acquisition from subepithelial lesions using a forward-viewing linear echoendoscope. Endoscopy 2014;46:39-45.

8. Beacon Endoscopic's BNX System for EUS FNA (Video). Available from: http://www.medgadget.com/2012/04/beaconendoscopics-bnx-system-for-eus-fna-video.html. [Last cited on 2014 Oct 12].

9. Bang JY, Hebert-Magee S, Trevino J, Ramesh J, Varadarajulu S. Randomized trial comparing the 22-gauge aspiration and 22-gauge biopsy needles for EUS-guided sampling of solid pancreatic mass lesions. Gastrointest Endosc 2012;76:321-7.

10. Fuccio L, Larghi A. Endoscopic ultrasound-guided fine needle aspiration: How to obtain a core biopsy? Endosc Ultrasound 2014;3:71-81.

11. Ramesh J, Bang JY, Hebert-Magee S, Trevino J, Eltoum I, Frost A, et al. Randomized trial comparing the flexible 19G and 25G needles for endoscopic ultrasound-guided fine needle aspiration of solid pancreatic mass lesions. Pancreas 2015;44:128-133.

12. Kaffes AJ, Chen RY, Tam W, Norton I, Cho S, Devereaux B, et al. A prospective multicenter evaluation of a new side-port endoscopic ultrasound-fine-needle aspiration in solid upper gastrointestinal lesions. Dig Endosc 2012;24:448-51.

13. Kaffes A, Corte C. Fine needle aspiration at endoscopic ultrasound with a novel side-port needle: A pilot experience. Therap Adv Gastroenterol 2012;5:89-94.

14. Bournet B, Selves J, Grand D, Danjoux M, Hanoun N, Cordelier P, et al. Endoscopic ultrasound-guided fine-needle aspiration biopsy coupled with a KRAS mutation assay using allelic discrimination improves the diagnosis of pancreatic cancer. J Clin Gastroenterol 2015;49:50-6.

15. Nie S, Lo A, Wu J, Zhu J, Tan Z, Simeone DM, et al. Glycoprotein biomarker panel for pancreatic cancer discovered by quantitative proteomics analysis. J Proteome Res 2014;13:1873-84.

16. Jabbar KS, Verbeke C, Hyltander AG, Sjövall H, Hansson GC, Sadik R. Proteomic mucin profiling for the identification of cystic precursors of pancreatic cancer. J Natl Cancer Inst 2014;106:djt439.

17. Al-Haddad M, DeWitt J, Sherman S, Schmidt CM, LeBlanc JK, McHenry L, et al. Performance characteristics of molecular (DNA) analysis for the diagnosis of mucinous pancreatic cysts. Gastrointest Endosc 2014;79:79-87.

18. Alsohaibani F, Girgis S, Sandha GS. Does onsite cytotechnology evaluation improve the accuracy of endoscopic ultrasound-guided fine-needle aspiration biopsy? Can J Gastroenterol 2009;23:26-30.

19. Varadarajulu S, Fraig M, Schmulewitz N, Roberts S, Wildi S, Hawes RH, et al. Comparison of EUS-guided 19-gauge Trucut needle biopsy with EUS-guided fine-needle aspiration. Endoscopy 2004;36:397-401.

20. Lee KR, Papillo JL, St John T, Eyerer GJ. Evaluation of the ThinPrep processor for fine needle aspiration specimens. Acta Cytol 1996;40:895-9.

21. Layfield LJ, Ehya H, Filie AC, Hruban RH, Jhala N, Joseph L, et al.
Utilization of ancillary studies in the cytologic diagnosis of biliary and pancreatic lesions: The Papanicolaou Society of Cytopathology Guidelines. Cytojournal 2014;11:4.

22. Iglesias-Garcia J, Lariño-Noia J, Abdulkader I, Domínguez-Muñoz JE. Rapid on-site evaluation of endoscopic-ultrasound-guided fine-needle aspiration diagnosis of pancreatic masses. World J Gastroenterol 2014;20:9451-7.

23. Erickson RA, Sayage-Rabie L, Beissner RS. Factors predicting the number of EUS-guided fine-needle passes for diagnosis of pancreatic malignancies. Gastrointest Endosc 2000;51:184-90.

24. DiMaio CJ, Buscaglia JM, Gross SA, Aslanian HR, Goodman AJ, Ho S, et al. Practice patterns in FNA technique: A survey analysis. World J Gastrointest Endosc 2014;6:499-505.

25. Jhala NC, Jhala DN, Chhieng DC, Eloubeidi MA, Eltoum IA. Endoscopic ultrasound-guided fine-needle aspiration. A cytopathologist's perspective. Am J Clin Pathol 2003;120:351-67.

26. Varadarajulu S, Holt BA, Bang JY, Hasan MK, Logue A, Tamhane A, et al. Training endosonographers in cytopathology: Improving the results of EUS-guided FNA. Gastrointest Endosc 2015;81:104-10.

27. Buxbaum JL, Eloubeidi MA, Lane CJ, Varadarajulu S, Linder A, Crowe AE, et al. Dynamic telecytology compares favorably to rapid onsite evaluation of endoscopic ultrasound fine needle aspirates. Dig Dis Sci 2012;57:3092-7.

28. Eisen GM, Dominitz JA, Faigel DO, Goldstein JA, Petersen BT, Raddawi HM, et al. Guidelines for credentialing and granting privileges for endoscopic ultrasound. Gastrointest Endosc 2001;54:811-4.

29. Paquin SC. Training in endoscopic ultrasound-guided fine needle aspiration. Endosc Ultrasound 2014;3:12-6.

30. Wani S, Hall M, Keswani RN, Aslanian HR, Casey B, Burbridge R, et al. Variation in aptitude of trainees in endoscopic ultrasonography, based on cumulative sum analysis. Clin Gastroenterol Hepatol 2014;pii:S1542-3565(14)01621-8.

31. Siddiqui UD, Rossi F, Rosenthal LS, Padda MS, Murali-Dharan V, Aslanian HR. EUS-guided FNA of solid pancreatic masses: A prospective, randomized trial comparing 22-gauge and 25-gauge needles. Gastrointest Endosc 2009;70:1093-7.

32. Camellini L, Carlinfante G, Azzolini F, Iori V, Cavina M, Sereni G, et al. A randomized clinical trial comparing $22 \mathrm{G}$ and $25 \mathrm{G}$ needles in endoscopic ultrasound-guided fine-needle aspiration of solid lesions. Endoscopy 2011;43:709-15.

33. Vilmann P, Saftoiu A, Hollerbach S, Skov BG, Linnemann D, Popescu CF, et al. Multicenter randomized controlled trial comparing the performance of 22 gauge versus 25 gauge EUS-FNA needles in solid masses. Scand J Gastroenterol 2013;48:877-83.

34. Varadarajulu S, Bang JY, Holt BA, Hasan MK, Logue A, Hawes RH, et al. The 25-gauge EUS-FNA needle: Good for on-site but poor for off-site evaluation? Results of a randomized trial. Gastrointest Endosc 2014;80:1056-63.

35. Madhoun MF, Wani SB, Rastogi A, Early D, Gaddam S, Tierney WM, et al. The diagnostic accuracy of 22-gauge and 25-gauge needles in endoscopic ultrasound-guided fine needle aspiration of solid pancreatic lesions: A meta-analysis. Endoscopy 2013;45:86-92.

36. Affolter KE, Schmidt RL, Matynia AP, Adler DG, Factor RE. Needle size has only a limited effect on outcomes in EUS-guided fine needle aspiration: A systematic review and meta-analysis. Dig Dis Sci 2013;58:1026-34

37. Yasuda I, Tsurumi H, Omar S, Iwashita T, Kojima Y, Yamada T, et al. Endoscopic ultrasound-guided fine-needle aspiration biopsy for lymphadenopathy of unknown origin. Endoscopy 2006;38:919-24.

38. Itoi T, Itokawa F, Sofuni A, Nakamura K, Tsuchida A, Yamao K, et al. Puncture of solid pancreatic tumors guided by endoscopic ultrasonography: A pilot study series comparing Trucut and 19-gauge and 22-gauge aspiration needles. Endoscopy 2005;37:362-6.

39. Song TJ, Kim JH, Lee SS, Eum JB, Moon SH, Park do H, et al. The prospective randomized, controlled trial of endoscopic ultrasound-guided fine-needle aspiration using $22 \mathrm{G}$ and $19 \mathrm{G}$ aspiration needles for solid pancreatic or peripancreatic masses. Am J Gastroenterol 2010;105:1739-45. 
40. Larghi A, Verna EC, Ricci R, Seerden TC, Galasso D, Carnuccio A, et al. EUS-guided fine-needle tissue acquisition by using a 19-gauge needle in a selected patient population: A prospective study. Gastrointest Endosc 2011;74:504-10.

41. Adler DG, Jacobson BC, Davila RE, Hirota WK, Leighton JA, Qureshi WA, et al. ASGE guideline: Complications of EUS. Gastrointest Endosc 2005;61:8-12.

42. Iwashita T, Nakai Y, Samarasena JB, Park do H, Zhang Z, Gu M, et al. High single-pass diagnostic yield of a new 25-gauge core biopsy needle for EUS-guided FNA biopsy in solid pancreatic lesions. Gastrointest Endosc 2013;77:909-15.

43. Larghi A, Verna EC, Stavropoulos SN, Rotterdam H, Lightdale CJ, Stevens PD. EUS-guided trucut needle biopsies in patients with solid pancreatic masses: A prospective study. Gastrointest Endosc 2004;59:185-90.

44. Iglesias-Garcia J, Poley JW, Larghi A, Giovannini M, Petrone MC, Abdulkader I, et al. Feasibility and yield of a new EUS histology needle: Results from a multicenter, pooled, cohort study. Gastrointest Endosc 2011;73:1189-96

45. Larghi A, Iglesias-Garcia J, Poley JW, Monges G, Petrone MC, Rindi G, et al. Feasibility and yield of a novel 22-gauge histology EUS needle in patients with pancreatic masses: A multicenter prospective cohort study. Surg Endosc 2013;27:3733-8.

46. Hucl T, Wee E, Anuradha S, Gupta R, Ramchandani M, Rakesh K, et al. Feasibility and efficiency of a new $22 \mathrm{G}$ core needle: A prospective comparison study. Endoscopy 2013;45:792-8.

47. Vanbiervliet G, Napoléon B, Saint Paul MC, Sakarovitch C, Wangermez M, Bichard $\mathrm{P}$, et al. Core needle versus standard needle for endoscopic ultrasound-guided biopsy of solid pancreatic masses: A randomized crossover study. Endoscopy 2014;46:1063-70.

48. Lee YN, Moon JH, Kim HK, Choi HJ, Choi MH, Kim DC, et al. Core biopsy needle versus standard aspiration needle for endoscopic ultrasound-guided sampling of solid pancreatic masses: A randomized parallel-group study. Endoscopy 2014;46:1056-62.

49. Bang JY, Ramesh J, Trevino J, Eloubeidi MA, Varadarajulu S. Objective assessment of an algorithmic approach to EUS-guided FNA and interventions. Gastrointest Endosc 2013;77:739-44.

50. Itoi T, Itokawa F, Kurihara T, Sofuni A, Tsuchiya T, Ishii K, et al. Experimental endoscopy: Objective evaluation of EUS needles. Gastrointest Endosc 2009;69:509-16.

51. Lee JK, Choi JH, Lee KH, Kim KM, Shin JU, Lee JK, et al. A prospective, comparative trial to optimize sampling techniques in EUS-guided FNA of solid pancreatic masses. Gastrointest Endosc 2013;77:745-51.

52. Sahai AV, Paquin SC, Gariépy G. A prospective comparison of endoscopic ultrasound-guided fine needle aspiration results obtained in the same lesion, with and without the needle stylet. Endoscopy 2010;42:900-3.

53. Rastogi A, Wani S, Gupta N, Singh V, Gaddam S, Reddymasu S, et al. A prospective, single-blind, randomized, controlled trial of EUS-guided FNA with and without a stylet. Gastrointest Endosc 2011;74:58-64.

54. Wani S, Gupta N, Gaddam S, Singh V, Ulusarac O, Romanas M, et al. A comparative study of endoscopic ultrasound guided fine needle aspiration with and without a stylet. Dig Dis Sci 2011;56:2409-14.

55. Trindade AJ, Berzin TM. Clinical controversies in endoscopic ultrasound. Gastroenterol Rep (Oxf) 2013;1:33-41.

56. Wallace MB, Kennedy T, Durkalski V, Eloubeidi MA, Etamad R, Matsuda K, et al. Randomized controlled trial of EUS-guided fine needle aspiration techniques for the detection of malignant lymphadenopathy. Gastrointest Endosc 2001;54:441-7.

57. Puri R, Vilmann P, Saftoiu A, Skov BG, Linnemann D, Hassan H, et al. Randomized controlled trial of endoscopic ultrasound-guided fine-needle sampling with or without suction for better cytological diagnosis. Scand J Gastroenterol 2009;44:499-504.

58. Nakai $Y$, Isayama $\mathrm{H}$, Chang KJ, Yamamoto N, Hamada T, Uchino R, et al. Slow pull versus suction in endoscopic ultrasound-guided fine-needle aspiration of pancreatic solid masses. Dig Dis Sci 2014;59:1578-85.

59. Polkowski M, Larghi A, Weynand B, Boustière C, Giovannini M, Pujol B, et al. Learning, techniques, and complications of endoscopic ultrasound (EUS)-guided sampling in gastroenterology: European Society of Gastrointestinal Endoscopy (ESGE) Technical Guideline. Endoscopy 2012;44:190-206.

60. Bang JY, Magee SH, Ramesh J, Trevino JM, Varadarajulu S. Randomized trial comparing fanning with standard technique for endoscopic ultrasound-guided fine-needle aspiration of solid pancreatic mass lesions. Endoscopy 2013;45:445-50.

61. Hikichi T, Irisawa A, Bhutani MS, Takagi T, Shibukawa G, Yamamoto G, et al. Endoscopic ultrasound-guided fine-needle aspiration of solid pancreatic masses with rapid on-site cytological evaluation by endosonographers without attendance of cytopathologists. J Gastroenterol 2009;44:322-8.

62. Klapman JB, Logrono R, Dye CE, Waxman I. Clinical impact of on-site cytopathology interpretation on endoscopic ultrasound-guided fine needle aspiration. Am J Gastroenterol 2003;98:1289-94.

63. Varadarajulu S, Hasan MK, Bang JY, Hebert-Magee S, Hawes RH. Endoscopic ultrasound-guided tissue acquisition. Dig Endosc 2014;26 Suppl 1:62-9.

64. Jhala NC, Jhala D, Eltoum I, Vickers SM, Wilcox CM, Chhieng DC, et al. Endoscopic ultrasound-guided fine-needle aspiration biopsy: A powerfu tool to obtain samples from small lesions. Cancer 2004;102:239-46.

65. Eloubeidi MA, Tamhane A. EUS-guided FNA of solid pancreatic masses: A learning curve with 300 consecutive procedures. Gastrointest Endosc 2005;61:700-8.

66. Eltoum IA, Alston EA, Roberson J. Trends in pancreatic pathology practice before and after implementation of endoscopic ultrasound-guided fine-needle aspiration: An example of disruptive innovation effect? Arch Pathol Lab Med 2012;136:447-53.

67. Chang KJ. Maximizing the yield of EUS-guided fine-needle aspiration. Gastrointest Endosc 2002;56:S28-34

68. DeWitt J, McGreevy K, Sherman S, LeBlanc J. Utility of a repeated EUS at a tertiary-referral center. Gastrointest Endosc 2008;67:610-9.

69. Eloubeidi MA, Varadarajulu S, Desai S, Wilcox CM. Value of repeat endoscopic ultrasound-guided fine needle aspiration for suspected pancreatic cancer. J Gastroenterol Hepatol 2008;23:567-70.

70. Nicaud M, Hou W, Collins D, Wagh MS, Chauhan S, Draganov PV. The utility of repeat endoscopic ultrasound-guided fine needle aspiration for suspected pancreatic cancer. Gastroenterol Res Pract 2010;2010:268290.

71. Reicher S, Boyar FZ, Albitar M, Sulcova V, Agersborg S, Nga V, et al. Fluorescence in situ hybridization and K-ras analyses improve diagnostic yield of endoscopic ultrasound-guided fine-needle aspiration of solid pancreatic masses. Pancreas 2011;40:1057-62.

72. Brand RE, Adai AT, Centeno BA, Lee LS, Rateb G, Vignesh S, et al. A microRNA-based test improves endoscopic ultrasound-guided cytologic diagnosis of pancreatic cancer. Clin Gastroenterol Hepatol 2014;12:1717-23.

73. Ranney N, Phadnis M, Trevino J, Ramesh J, Wilcox CM, Varadarajulu S. Impact of biliary stents on EUS-guided FNA of pancreatic mass lesions. Gastrointest Endosc 2012;76:76-83.

74. Siddiqui AA, Fein M, Kowalski TE, Loren DE, Eloubeidi MA Comparison of the influence of plastic and fully covered metal biliary stents on the accuracy of EUS-FNA for the diagnosis of pancreatic cancer. Dig Dis Sci 2012;57:2438-45.

75. Fisher JM, Gordon SR, Gardner TB. The impact of prior biliary stenting on the accuracy and complication rate of endoscopic ultrasound fine-needle aspiration for diagnosing pancreatic adenocarcinoma. Pancreas 2011;40:21-4.

76. Claudon M, Dietrich CF, Choi BI, Cosgrove DO, Kudo M, Nolsøe CP, et al. Guidelines and good clinical practice recommendations for Contrast Enhanced Ultrasound (CEUS) in the liver - Update 2012: A WFUMB-EFSUMB initiative in cooperation with representatives of AFSUMB, AIUM, ASUM, FLAUS and ICUS. Ultrasound Med Biol 2013;39:187-210.

77. Popescu A, Saftoiu A. Can elastography replace fine needle aspiration? Endosc Ultrasound 2014;3:109-17.

78. Giovannini M, Thomas B, Erwan B, Christian P, Fabrice C, Benjamin E et al. Endoscopic ultrasound elastography for evaluation of lymph nodes 
and pancreatic masses: A multicenter study. World J Gastroenterol 2009;15:1587-93.

79. Iglesias-Garcia J, Larino-Noia J, Abdulkader I, Forteza J, Dominguez-Munoz JE. EUS elastography for the characterization of solid pancreatic masses. Gastrointest Endosc 2009;70:1101-8.

80. Dietrich CF, Jenssen C. Endoscopic ultrasound-guided sampling in gastroenterology: European society of gastrointestinal endoscopy technical guidelines. Endosc Ultrasound 2013;2:117-22.

81. Kitano M, Sakamoto H, Kudo M. Contrast-enhanced endoscopic ultrasound. Dig Endosc 2014;26 Suppl 1:79-85.

82. Hocke M, Schulze E, Gottschalk P, Topalidis T, Dietrich CF. Contrast-enhanced endoscopic ultrasound in discrimination between focal pancreatitis and pancreatic cancer. World J Gastroenterol 2006; 12:246-50.

83. Hocke M, Schmidt C, Zimmer B, Topalidis T, Dietrich CF, Stallmach A. Contrast enhanced endosonography for improving differential diagnosis between chronic pancreatitis and pancreatic cancer. Dtsch Med Wochenschr 2008;133:1888-92.

84. Gheonea DI, Streba CT, Ciurea T, Saftoiu A. Quantitative low mechanical index contrast-enhanced endoscopic ultrasound for the differential diagnosis of chronic pseudotumoral pancreatitis and pancreatic cancer. BMC Gastroenterol 2013;13:2.

85. Dietrich CF, Ignee A, Braden B, Barreiros AP, Ott M, Hocke M. Improved differentiation of pancreatic tumors using contrast-enhanced endoscopic ultrasound. Clin Gastroenterol Hepatol 2008;6:590-597.e1.

86. Saftoiu A, Iordache SA, Gheonea DI, Popescu C, Malos A, Gorunescu F, et al. Combined contrast-enhanced power Doppler and real-time sonoelastography performed during EUS, used in the differential diagnosis of focal pancreatic masses (with videos). Gastrointest Endosc 2010;72:739-47.

87. Corless CL. Gastrointestinal stromal tumors: What do we know now? Mod Pathol 2014;27 Suppl 1:S1-16.

88. Corless CL, Barnett CM, Heinrich MC. Gastrointestinal stromal tumours: Origin and molecular oncology. Nat Rev Cancer 2011;11:865-78.

89. Eisenberg BL, Pipas JM. Gastrointestinal stromal tumor - Background, pathology, treatment. Hematol Oncol Clin North Am 2012;26:1239-59.

90. Larghi A, Capurso G, Carnuccio A, Ricci R, Alfieri S, Galasso D, et al. Ki-67 grading of nonfunctioning pancreatic neuroendocrine tumors on histologic samples obtained by EUS-guided fine-needle tissue acquisition: A prospective study. Gastrointest Endosc 2012;76:570-7.

91. Biankin AV, Kench JG, Colvin EK, Segara D, Scarlett CJ, Nguyen NQ, et al. Expression of S100A2 calcium-binding protein predicts response to pancreatectomy for pancreatic cancer. Gastroenterology 2009;137:558-68, 568.e1.

92. Villanueva RR, Nguyen-Ho P, Nguyen GK. Needle aspiration cytology of acinar-cell carcinoma of the pancreas: Report of a case with diagnostic pitfalls and unusual ultrastructural findings. Diagn Cytopathol $1994 ; 10: 362-4$

93. Gleeson FC, Kipp BR, Caudill JL, Clain JE, Clayton AC, Halling KC, et al. False positive endoscopic ultrasound fine needle aspiration cytology: Incidence and risk factors. Gut 2010;59:586-93.

94. Bang JY, Varadarajulu S. Neoplasia in chronic pancreatitis: How to maximize the yield of endoscopic ultrasound-guided fine needle aspiration. Clin Endosc 2014;47:420-4.

95. Varadarajulu S, Tamhane A, Eloubeidi MA. Yield of EUS-guided FNA of pancreatic masses in the presence or the absence of chronic pancreatitis. Gastrointest Endosc 2005;62:728-36.

96. Das A, Sivak MV Jr, Chak A. Cervical esophageal perforation during EUS: A national survey. Gastrointest Endosc 2001;53:599-602.

97. Fujii LL, Levy MJ. Basic techniques in endoscopic ultrasound-guided fine needle aspiration for solid lesions: Adverse events and avoiding them. Endosc Ultrasound 2014;3:35-45.

98. Eloubeidi MA, Tamhane A, Varadarajulu S, Wilcox CM. Frequency of major complications after EUS-guided FNA of solid pancreatic masses: A prospective evaluation. Gastrointest Endosc 2006;63:622-9.

99. Annema JT, Veseliç M, Versteegh MI, Rabe KF. Mediastinitis caused by EUS-FNA of a bronchogenic cyst. Endoscopy 2003;35:791-3.
100. Diehl DL, Cheruvattath R, Facktor MA, Go BD. Infection after endoscopic ultrasound-guided aspiration of mediastinal cysts. Interact Cardiovasc Thorac Surg 2010;10:338-40.

101. Wang KX, Ben QW, Jin ZD, Du YQ, Zou DW, Liao Z, et al. Assessment of morbidity and mortality associated with EUS-guided FNA: A systematic review. Gastrointest Endosc 2011;73:283-90.

102. Reddymasu S, Oropeza-Vail MM, Williamson S, Jafri F, Olyaee M. Pancreatic leak after endoscopic ultrasound guided fine needle aspiration managed by transpapillary pancreatic duct stenting. JOP 2011;12:489-90.

103. Gress F, Michael H, Gelrud D, Patel P, Gottlieb K, Singh F, et al. EUS-guided fine-needle aspiration of the pancreas: Evaluation of pancreatitis as a complication. Gastrointest Endosc 2002;56:864-7.

104. Prachayakul V, Aswakul P. Successful endoscopic treatment of iatrogenic biloma as a complication of endosonography-guided hepaticogastrostomy: The first case report. J Interv Gastroenterol 2012;2:202-4

105. Giovannini M, Bories E. EUS-Guided Biliary Drainage. Gastroenterol Res Pract 2012;2012:348719.

106. Kahaleh M. Training the next generation of advanced endoscopists in EUS-guided biliary and pancreatic drainage: Learning from master endoscopists. Gastrointest Endosc 2013;78:638-41.

107. Chong A, Venugopal K, Segarajasingam D, Lisewski D. Tumor seeding after EUS-guided FNA of pancreatic tail neoplasia. Gastrointest Endosc 2011;74:933-5.

108. Paquin SC, Gariépy G, Lepanto L, Bourdages R, Raymond G, Sahai AV. A first report of tumor seeding because of EUS-guided FNA of a pancreatic adenocarcinoma. Gastrointest Endosc 2005;61:610-1.

109. Horwhat JD, Paulson EK, McGrath K, Branch MS, Baillie J, Tyler D, et al. A randomized comparison of EUS-guided FNA versus CT or US-guided FNA for the evaluation of pancreatic mass lesions. Gastrointest Endosc 2006;63:966-75.

110. Ngamruengphong S, Xu C, Woodward TA, Raimondo M, Stauffer JA, Asbun HJ, et al. Risk of gastric or peritoneal recurrence, and long-term outcomes, following pancreatic cancer resection with preoperative endosonographically guided fine needle aspiration. Endoscopy 2013;45:619-26.

111. Yoon WJ, Daglilar ES, Fernández-del Castillo C, Mino-Kenudson M, Pitman MB, Brugge WR. Peritoneal seeding in intraductal papillary mucinous neoplasm of the pancreas patients who underwent endoscopic ultrasound-guided fine-needle aspiration: The PIPE Study. Endoscopy 2014;46:382-7.

112. Ikezawa K, Uehara H, Sakai A, Fukutake N, Imanaka K, Ohkawa K, et al. Risk of peritoneal carcinomatosis by endoscopic ultrasound-guided fine needle aspiration for pancreatic cancer. J Gastroenterol 2013;48:966-72.

113. Micames C, Jowell PS, White R, Paulson E, Nelson R, Morse M, et al. Lower frequency of peritoneal carcinomatosis in patients with pancreatic cancer diagnosed by EUS-guided FNA vs. percutaneous FNA. Gastrointest Endosc 2003;58:690-5.

114. El Chafic AH, Dewitt J, Leblanc JK, El Hajj II, Cote G, House MG, et al. Impact of preoperative endoscopic ultrasound-guided fine needle aspiration on postoperative recurrence and survival in cholangiocarcinoma patients. Endoscopy 2013;45:883-9.

115. Fritscher-Ravens A, Broering DC, Sriram PV, Topalidis T, Jaeckle S, Thonke F, et al. EUS-guided fine-needle aspiration cytodiagnosis of hilar cholangiocarcinoma: A case series. Gastrointest Endosc 2000;52:534-40.

116. Heimbach JK, Sanchez W, Rosen CB, Gores GJ. Trans-peritoneal fine needle aspiration biopsy of hilar cholangiocarcinoma is associated with disease dissemination. HPB (Oxford) 2011;13:356-60.

117. Navaneethan U, Njei B, Venkatesh PG, Lourdusamy V, Sanaka MR Endoscopic ultrasound in the diagnosis of cholangiocarcinoma as the etiology of biliary strictures: A systematic review and meta-analysis. Gastroenterol Rep (Oxf) 2014;pii:gou057.

How to cite this article: Tharian B, George N, Canipe A, Holt B, Krall K, Hébert-Magee $\mathrm{S}$, et al. Endoscopic ultrasound-guided fine-needle tissue acquisition - A review and update of literature. J Dig Endosc 2015;6:1-10.

Source of Support: Nil, Conflict of Interest: None declared. 